COMMENT. All children with neuroblastoma and opsoclonus-myoclonus and ataxia had an excellent surgical outcome and their eye movement disorder eventually responded to ACTH. The majority have long-term learning and behavioral problems, requiring special remedial education and behavioral intervention. Immunizations should be delayed or withheld when possible to avoid relapse of opsoclonus and ataxia.

\title{
CRANIOPHARYNGIOMA: RECURRENCE FACTORS
}

Factors predictive of recurrence and functional outcome were determined in a retrospective clinicopathological analysis of 56 patients (26 children and 30 adults) operated on for craniopharyngioma since 1981 at New York University Medical Center. Children underwent gross total resection (GTR) of tumor more frequently than adults (77\% cf $27 \%$ ). Tumors were almost all adamantinomatous in children, whereas in adults, two thirds were adamantinomatous and one third were squamous papillary. Brain invasion was most frequent with the adamantinomatous craniopharyngiomas; invasion had occurred in $46 \%$ of the children compared with $17 \%$ of adults. Subtotal resection was associated with a higher rate of recurrence compared with total resection. Brain invasion had no effect on recurrence rate in totally resected cases. Functional, visual, and endocrine outcomes were not sacrificed by total resection of tumor. (Weiner $\mathrm{HL}$ et al. Craniopharyngiomas: a clinicopathological analysis of factors predictive of recurrence and functional outcome. Neurosurgery December 1994;35:1001-1011). (Reprints: Howard L Weiner MD, Dept of Neurosurgery, New York University Medical Center, 550 First Ave, New York, NY 10016).

COMMENT. The single most important factor predictive of craniopharyngioma recurrence is the extent of surgical resection. Total compared to subtotal resection has a significantly lower recurrence rate without affecting functional outcome. Brain invasion does not predict higher recurrence provided the tumor is totally resected.

Estogen Receptor Gene Expression. Craniopharyngiomas are histologically benign neoplasms of the sellar region that frequently show local invasion of brain tissue. In a collaborative study at the University of Toronto, Canada, the Mayo Clinic, and the University of Virginia, Charlottesville, 23 surgically removed craniopharyngiomas uniformally expressed the estrogen receptor gene. A possible hormonal component to the genesis and progression of craniopharyngiomas and investigation of hormonal therapy are suggested.

\section{SPEECH AND LANGUAGE DISORDERS}

\section{CEREBELLAR MUTISM}

Of a series of 15 children operated for cerebellar tumor at University Hospital Rotterdam-Dijkzigt, The Netherlands, 5 developed "cerebellar mutism" and subsequent dysarthria after surgery, and 2 had mild speech problems. Of 8 without speech problems, 7 had astrocytomas, with involvement of a cerebellar hemisphere. Of the 5 with mutism, 4 had medulloblastomas, and all had tumors that lined the fourth ventricle. Mutism was delayed for 1 to 2 days after surgery. Alternating movements of the tongue were impaired but no paresis of bulbar muscles was evident in mute patients. The duration of mutism 
varied from 3 to 8 weeks. Speech was regained suddenly and unexpectedly, and the severe dysarthria that followed lasted for 1 to 5 weeks. Recovery was associated with normalization of tongue movements. Factors predictive of mutism were 1) tumor filling and adherence to the floor of the fourth ventricle; 2) shunting for hydrocephalus prior to surgery; and 3) postsurgical edema of the pontine tegmentum. (van Dongen HR et al. The syndrome of 'cerebellar' mutism and subsequent dysarthria. Neurology Nov 1994;44:20402046). (Reprints: Dr HR van Dongen, Department of Neurology, University Hospital Rotterdam-Dijkzigt, dr Molewaterplein 40,3015 GD Rotterdam, The Netherlands).

COMMENT. The authors cite 36 cases of cerebellar mutism from the literature. An additional 2 cases are reported in Progress in Pediatric Neurology Vol. II, Chicago, PNB Publishers, 1994, pp219-220. The complication was correlated with the amount of the posterior vermis resected. One tumor was a medulloblastoma and the other an astrocytoma. Speech was regained after 2 months.

A case of mutism followed by dysarthria and agrammatic speech is reported in an adult after a right cerebellar infarction. (Silveri MC et al. The cerebellum contributes to linguistic production: a case of agrammatic speech following a right cerebellar lesion. Neurology Nov 1994;44:2047-2050).

\section{BEHAVIOR AND ATTENTION DISORDERS}

\section{FOOD COLORING AND BEHAVIOR}

The association between the ingestion of tartrazine synthetic food coloring and behavioral change in children referred for assessment of hyperactivity was investigated at the Royal Children's Hospital, University of Melbourne, Australia. Two hundred hyperactive children whose parents had noted changes in behavior with diet were included in a 6-week open trial of a diet free of synthetic colorings. The parents of 150 reported behavioral improvement with the diet, and deterioration when foods containing synthetic colorings were introduced. A 30 -item inventory with 5 behavior clusters (irritability, sleeplessness, restlessness, aggression, and inattention) discriminated between dye ingestion and placebo. A double-blind, placebocontrolled, 21-day study of 34 reactive children, using each child as his or her own control, identified 24 atopic children as clear reactors to tartrazine at all six dose levels, between 1 and $50 \mathrm{mg}$. They were irritable and restless and had sleep disturbance. A dose response was obtained and the effect was prolonged with doses $>10 \mathrm{mg}$. (Rowe KS, Rowe KJ. Synthetic food coloring and behavior: a dose response effect in a double-blind, placebo-controlled, repeated-measures study. I Pediatr Nov 1994;125:691-698). (Reprints: Katherine S Rowe MBBS, Department of Pediatrics, University of Melbourne, Royal Children's Hospital, Parkville, Victoria 3052, Australia).

COMMENT. The authors appear to have demonstrated a relation between tartrazine ingestion and behavior in 24 atopic children,aged 2 to 14 years. Parents were found to be reliable observers and raters of their children's behavior. The strict criteria of ADDH, and a score of $>15$ on the Conners Abbreviated Parent-Teacher Questionnaire, required for inclusion in many previous studies of diet and hyperactivity may have missed some reactors, accounting for inconclusive results. Further, the 